\title{
Sonic hedgehog signaling in the development of the mouse hypothalamus
}

\author{
Sandra Blaess ${ }^{1 *}$, Nora Szabó ${ }^{2}$, Roberta Haddad-Tóvolli ${ }^{3}$, Xunlei Zhou ${ }^{3}$ and Gonzalo Álvarez-Bolado ${ }^{3 *}$ \\ 'Neurodevelopmental Genetics, Institute of Reconstructive Neurobiology, University of Bonn, Bonn, Germany \\ ${ }^{2}$ Department of Neurobiology and Development, Institut de Recherches Cliniques de Montréal, Montréal, OC, Canada \\ ${ }^{3}$ Department of Medical Cell Biology, Institute of Anatomy and Cell Biology, University of Heidelberg, Heidelberg, Germany
}

\section{Edited by:}

Valery Grinevich, German Cancer

Research Center DKFZ and

University of Heidelberg, Germany

Reviewed by:

Sara Ferrando, University of Genoa,

Italy

Clemens Martin Kiecker, King's

College London, UK

*Correspondence:

Sandra Blaess,

Neurodevelopmental Genetics, Institute of Reconstructive

Neurobiology, University of Bonn,

Sigmund-Freud-Straße 25, D-53127

Bonn, Germany

e-mail: sandra.blaess@uni-bonn.de;

Gonzalo Álvarez-Bolado,

Department of Medical Cell Biology,

Institute of Anatomy and Cell

Biology, University of Heidelberg,

Im Neuenheimer Feld 307, D-69120

Heidelberg, Germany

e-mail:alvarez@

ana.uni-heidelberg.de
The expression pattern of Sonic Hedgehog (Shh) in the developing hypothalamus changes over time. Shh is initially expressed in the prechordal mesoderm and later in the hypothalamic neuroepithelium-first medially, and then in two off-medial domains. This dynamic expression suggests that Shh might regulate several aspects of hypothalamic development. To gain insight into them, lineage tracing, (conditional) gene inactivation in mouse, in ovo loss- and gain-of-function approaches in chick and analysis of Shh expression regulation have been employed. We will focus on mouse studies and refer to chick and fish when appropriate to clarify. These studies show that Shh-expressing neuroepithelial cells serve as a signaling center for neighboring precursors, and give rise to most of the basal hypothalamus (tuberal and mammillary regions). Shh signaling is initially essential for hypothalamic induction. Later, Shh signaling from the neuroepithelium controls specification of the lateral hypothalamic area and growth-patterning coordination in the basal hypothalamus. To further elucidate the role of Shh in hypothalamic development, it will be essential to understand how Shh regulates the downstream Gli transcription factors.

Keywords: chick, development, Gli, hypothalamus, lineage, mouse, phenotype, Shh

\section{EXPRESSION PATTERN OF Shh IN THE DEVELOPING HYPOTHALAMUS}

Already the first studies characterizing mouse embryonic Sonic Hedgehog (Shh) expression showed that it is dynamic in the developing forebrain, a fact that immediately led to speculation as to the function of these domains (Echelard et al., 1993; Chang et al., 1994; Shimamura et al., 1995; Goodrich et al., 1996; Platt et al., 1997; Figures 1A-D). Based on these early studies and our own detailed hypothalamus expression analysis (Szabó et al., 2009; Alvarez-Bolado et al., 2012), we divide the expression of Shh in the mouse neural tube into distinct patterns (Figures 1A-D). Similar patterns are found in chick (Dale et al., 1997; Ohyama et al., 2004, 2008; Placzek and Briscoe, 2005; Manning et al., 2006) and zebrafish (Barth and Wilson, 1995; Mathieu et al., 2002) embryos. Note that the dates in embryonic days (E) are approximate, and, for some events, differences of up to 1 day can be found between studies. The influence of Shh on the hypothalamus starts with the onset of Shh expression in the underlying head process (Figures 1A,E, early pattern) (Aoto et al., 2009) (chick HH stage [st] 4). This is accompanied by the almost immediate onset of Gli1 expression in the overlying neural ectoderm, starting at E7.5 (Figure 1E; Hui et al., 1994). Since Gli1 expression is diagnostic of Shh pathway activation (Goodrich et al., 1996; Marigo and Tabin, 1996; Marigo et al., 1996; Lee et al., 1997), Gli1 expression indicates that Shh signaling is involved in specifiying this neuroectodermal region. At E8.5, the neuroectodermal cells in the ventral midline start to express Shh (i.e., neuroepithelial Shh makes its appearance) (chick st 7-10; zebrafish 5 somites) while Gli1 expression is downregulated medially (Christ et al., 2012; Figure 1F). Later, Shh expression is downregulated in the ventral midline of the basal hypothalamus and Shh is expressed in two domains bilaterally to the midline (Figure 1G, late pattern) (chick st 15 and later; zebrafish 22-28 somites). We still lack detailed studies of Gli1 expression in the alar and basal hypothalamus at E9.5-E10.5. The scarce expression data found in the literature (Furimsky and Wallace, 2006; Aoto et al., 2009) are imprecise in terms of hypothalamic region as well as plane of section. In chick, the off-medial Shh-expressing cells migrate anteriorly from the diencephalic/mesencephalic junction and start to express Shh once they reach their final position in the hypothalamic primordium (Manning et al., 2006). It is important to note the expression of Shh is restricted to the 

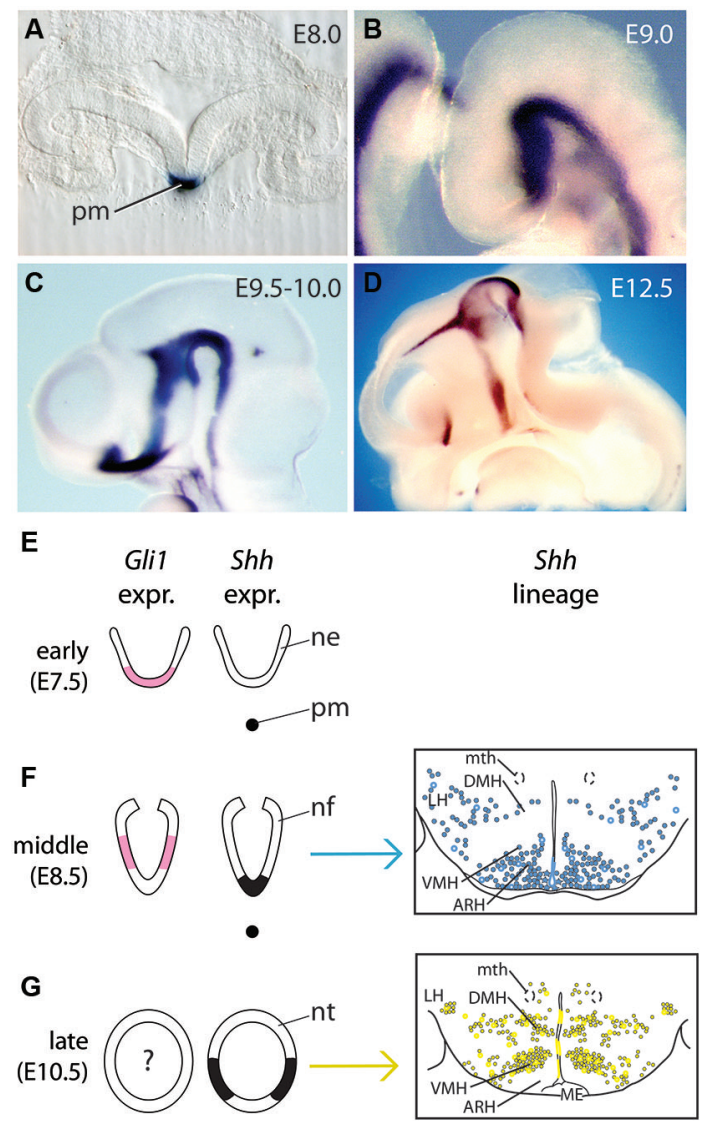

FIGURE 1 | Shh expression and lineage during forebrain development (A) Shh expression in the prechordal plate seen on a transverse section of the head folds of an E8.0 embryo. pm, prechordal mesoderm. (B-D) In situ hybridization detection of Shh on wild type mouse brains. In (C) and (D), the heads have been saggitally halved to show the neuroepithelium-ventricular zone on the inner side of the brain; rostral to the left. (B) Continuous Shh expression domain in the ventral forebrain at E9.0. (C) Shh expression is downregulated in the basal hypothalamus at E9.5-E10.0. (D) Shh hypothalamic expression at E12.5. (E-G) Diagrams of Shh (black) and Gli1 (pink) expression domains in the presumptive hypothalamus at three embryonic ages (only two for Glit), together with their progeny represented in schemas of transverse sections through the hypothalamus (middle, blue in (F); late, yellow in (G)). (Right side panels in (F), (G), are from Alvarez-Bolado et al., 2012). Abbreviations: ARH, arcuate nucleus; DMH, dorsomedial nucleus; $\mathrm{LH}$, lateral hypothalamic area; $\mathrm{ME}$, median eminence; mth, mammillothalamic tract; ne, neuroectoderm; nf, neural folds; nt, neural tube; pm, prechordal mesoderm; VMH, ventromedial nucleus.

ventricular zone, i.e., differentiated neurons or glia cells cease to express Shh. From here on, we will refer to the spatialtemporal classification of Shh expression described above to explain the results of lineage tracing and gene inactivation studies.

\section{LINEAGE OF Shh-EXPRESSING AND -RESPONDING PROGENITORS IN THE HYPOTHALAMUS}

Shh-expressing cells in the ventral midline (floor plate) of the spinal cord and hindbrain appear to function solely as organizers, i.e., they induce and pattern neighboring precursors but do not contribute progeny to the developing neural tissue (Joksimovic et al., 2009). In contrast, Shh-expressing cells in the mesencephalic floor plate give rise to neurons (Joksimovic et al., 2009; Blaess et al., 2011). To investigate whether Shhexpressing cells contribute to the hypothalamus and whether precursors in the medial vs. lateral Shh-expressing domain give rise to different hypothalamic regions, we used the Shh-CreER mouse line in combination with Cre-inducible reporters for an inducible genetic fate mapping approach (Alvarez-Bolado et al., 2012; Figures 1F,G). We mapped the distribution of fatemapped cells in late embryonic and adult brains after tamoxifen administration (TM) (to activate Cre and induce reporter gene expression) at selected stages between E7.5 and E12.5. Based on these data, we were able to characterize the changing lineages that are derived from Shh-expressing cells. The timing of these changes is largely consistent with the early, middle and late patterns of Shh expression. We found that initially (TM at E7.5, corresponding to early pattern), very few cells are derived from Shh-expressing precursors, all of them localized to the posterior hypothalamus. With TM at E8.5 (corresponding to middle pattern), the progeny of Shh-expressing precursors contribute to the mammillary and tuberal regions. At later stages (TM at E9.5, E10.5, E11.5 or E12.5; corresponding to late pattern), Shh-expressing precursors give rise to cells in the preoptic area and in the posterior hypothalamic anlage, but to only few cells in the mammillary nucleus and ventral midline of the tuberal region. Precursors labeled with TM at E12.5 generate relatively few labeled cells and most of these have a morphology indicative of astrocytes. Interestingly, Shh-expressing precursors do not contribute any progeny to the anterior hypothalamic region at any of the labeling stages.

The telencephalic domain of Shh expression corresponds to the preoptic area and the medial ganglionic emminence. Shhexpressing precursors in the medial ganglionic eminence give rise to the globus pallidus (Flandin et al., 2010; Nóbrega-Pereira et al., 2010) while the Shh-expressing domain in the preoptic area generates septal neurons (Wei et al., 2012) and preoptic astrocytes (Alvarez-Bolado et al., 2012). Lineage tracing of the lateral Shh-expressing precursor domain in the chick show that one of the neuronal populations generated from this domain are hypothalamic dopaminergic neurons (Ohyama et al., 2005).

A detailed characterization of the lineage of Shh-responding (Gli1-expressing) cells in the hypothalamus is lacking. Aoto et al. (2009) used genetic inducible fate mapping with a Gli1CreER line to investigate the lineage of Gli1-expression in craniofacial tissues, but the authors also provide some results on the tuberal hypothalamus. Gli1-expressing precursors labeled with $\mathrm{TM}$ at E8.5 give rise to progeny in the mediolateral tuberal hypothalamus (except for the midline). At later stages (TM at E9.5 and E11.5), Gli1-expressing precursors do not contribute to the tuberal hypothalamus. More anterior or posterior areas of the hypothalamus or the fate of Gli1-expressing cells before E8.5 or after E11.5 have not been assessed in this study. 


\section{PHENOTYPES OF MOUSE MUTANTS LACKING Shh EXPRESSION IN THE FOREBRAIN/FUNCTION OF Shh SIGNALING IN THE DEVELOPMENT OF THE BASAL HYPOTHALAMUS}

The phenotype of the Shh knock-out mouse mutant was published in 1996 (Chiang et al., 1996) and famously showed the loss of the ventral portion of the neural tube. The hypothesis that Shh was a key ventralizer, initially based on the Shh expression domain, was confirmed. The loss of ventral midline structures leads to a particularly severe forebrain phenotype: Shh knockout mice have a single fused telencephalic vesicle and a single fused optic cup (holoprosencephaly) (Chiang et al., 1996). Studies in chicken uncovered a key role of Shh (together with other determinants like bone morphogenetic proteins (BMPs)) secreted by the prechordal plate in hypothalamic induction and specifically in the specification of the hypothalamic ventral midline (Dale et al., 1997; Pera and Kessel, 1997).The dissection between the effects of Shh secreted by the axial mesoderm in the mouse however (notochord and prechordal plate; nonneural Shh) or by the neural tube itself (neural Shh) started more than a decade later. Analysis of Shh knock-out embryos and embryos chimeric for Shh knock-out cells showed that Shh signaling is non-cell autonomously required to maintain the prechordal mesoderm. In the absence of Shh, but also after lesions of the prechordal mesoderm, the forebrain midline does not develop (Aoto et al., 2009), indicating that Shh signaling from the prechordal mesoderm is essential to induce forebrain midline structures. To investigate the role of Shh secreted from the hypothalamic primordium, several conditional knockout mouse models were established. Using a Shh floxed allele (Dassule et al., 2000; Lewis et al., 2004) and a Foxb1-Cre mouse line (Zhao et al., 2007), which drives Cre expression in the forebrain neuroepithelium starting around E8.0, Szabó et al. (2009) generated a neuroepithelial specific inactivation of Shh in the hypothalamic primordium. Analysis of these conditional Shh mutants showed that neural Shh is required for the specification of the lateral hypothalamus and in particular of the hypocretin/orexin neurons. The medial portion of the basal hypothalamus (tuberal and mammillary regions) was severely reduced in size and showed specification defects (Szabó et al., 2009).

Nkx2-1 is a specific marker of the hypothalamic primordium starting to be expressed at E8.0 (Shimamura et al., 1995). Using a Nkx2-1-Cre mouse line (Xu et al., 2008) to inactivate Shh, Shimogori et al. (2010) generated a second conditional mutant mouse model lacking Shh expression in the hypothalamic primordium. The phenotype of these mutants confirmed the requirement of neural Shh for normal hypothalamic growth and for the specification of the basal portion; alterations in lateral hypothalamic markers were also found. In addition, the developmental transcriptome of the mouse hypothalamus was analyzed with microarrays and was used to generate a genomic atlas resource for the study of hypothalamus development (Shimogori et al., 2010).

Zhao et al. (2012) inactivated Shh in the hypothalamic neuroepithelium using the SBE2-Cre mouse line. SBE2 is a hypothalamus-specific upstream regulatory element of Shh (Jeong et al., 2006). The results of the mutant analysis confirmed previous results (Szabó et al., 2009; Shimogori et al., 2010). Additionally, the study demonstrated that deficiency in neural Shh causes septo-optic dysplasia, a congenital brain anomaly that leads to defects in the pituitary, the optic nerve, and the midline of the forebrain.

\section{THE Shh-Gli CODE IN THE DEVELOPMENT OF THE HYPOTHALAMUS}

Shh signaling is transduced by the two transmembrane receptors Patched (Ptch) and Smoothened and the Gli zinc finger transcription factors (Gli1-3). In the presence of Shh, Gli2 acts as a strong activator in the pathway. Gli3 acts primarily as a repressor of Shh target genes; in presence of Shh the Gli3 repressor function is attenuated and Gli3 can even function as a weak activator. Gli1 (Figures 1E-G, right panels, pink) contributes to the activation of the pathway, but it is only expressed in cells in which Gli2 (or Gli3) activator is already present and, as described above, can be used as a readout for the pathway (Fuccillo et al., 2006). In the spinal cord, midbrain and telencephalon, the dissection of the relative contribution of Gli activator and repressor function downstream of Shh have given considerable insight into the role of Shh signaling in the specification of these regions. The analysis of this Shh-Gli code in the hypothalamus is still rudimentary. Although Shh is essential for maintenance of prechordal plate and induction of ventral midline (Aoto et al., 2009), analysis of Gli2 null mutants indicates that Shh expression in the hypothalamus is independent of Shh signaling from underlying prechordal mesoderm (Matise et al., 1998). In Gli2 knock-out mutants, the bilateral Shh expression domain normally observed after E9.5 (Figure 1G) is fused to a single midline domain in the basal hypothalamus at E11.5, indicating that Gli2-mediated Shh signaling is required for the induction of the ventral midline, but not for the induction of Shh expression in the tuberal hypothalamic neuroepithelium per se (Park et al., 2000). Nkx2-1 expression is reduced and shifted medially in these mutants. Additional inactivation of Gli1 on the Gli2 knock-out background results in a more severe phenotype; the Nkx2-1 and Shh expression domains are completely missing and the size of the tuberal hypothalamic primordium is severely reduced. Gli1 appears to be primarily important for the partial rescue of Gli2 loss-of-function: mice in which Gli1 is inactivated and which are heterozygous for Gli2 do not have an obvious phenotype in the tuberal hypothalamus (Park et al., 2000).

Evidence that Gli3 plays a role in hypothalamic development comes from a human malformation syndrome. PallisterHall syndrome is associated with several malformations including polydactyly, imperforated anus and hypothalamic hamartomas (a non-cancerous tumor in the tuberal hypothalamus), which develop typically during early gestation (33-41 days) (Clarren et al., 1980; Hall et al., 1980). The underlying mutation in the Gli3 gene results in the production of a truncated form of Gli3 protein acting as a constitutive repressor (Meyer and Roelink, 2003 ) indicating that the precise regulation of Gli3 repressor levels is essential for normal hypothalamic development in humans. However, mice generated to have this mutation in Gli3 do not 
develop hypothalamic hamartomas, even though they have most of the other malformations characteristic of the Pallister-Hall syndrome (Böse et al., 2002). Evidence that Shh-signaling mediated regulation of Gli3 repressor levels is essential for the induction of ventral forebrain structures comes from the analysis of Shh knock-out and Shh/Gli3 double mutant mice: in addition to the loss of ventral midline structures in Shh knock-out mice (Nkx2-1 positive) ventrolateral domains ( $D l \times 2$ and Gsh2 positive), are severely reduced. If Gli3 is inactivated in addition to $S h h$, all three markers are expressed in their normal ventral domains (Rallu et al., 2002b). Whether defects in hypothalamic development in Shh knock-out mice can be rescued by removal of Gli3 has not been investigated. The effects of Gli3 loss-of-function on hypothalamic development in mouse have not been assessed directly, but histological sections through the diencephalon point to the absence of a severe phenotype in Gli3 null mutants (Theil et al., 1999). In chick, the antagonistic functions of Gli3 activator and repressor have been analyzed by means of their effect on Pax7 expression in the developing hypothalamus. Pax7 is expressed in the lateral hypothalamus, but only at stage 30. Gli3 repressor induces $P a x 7$ expression, while Gli activator inhibits Pax7 expression. Gli3 expression is upregulated by BMP7 and in addition to Gli3 repressor, activation of BMP signaling is necessary for the induction of the Pax7 positive cell fate (Ohyama et al., 2008).

\section{NEURAL Shh IN THE PREOPTIC AREA AND alar HYPOTHALAMUS}

The preoptic area is classically assigned to the hypothalamus, according to its adult functionality, but embryologically it develops from the telencephalon (Puelles et al., 2012). Both this region and the classical "anterior" (or postoptic) region belong to the alar portion of the forebrain. Shh is expressed in this region of the neural tube as an isolated domain corresponding to the medial ganglionic eminence and preoptic area. These regions generate neurons that migrate to other areas of the telencephalon (Flandin et al., 2010; Nóbrega-Pereira et al., 2010; Wei et al., 2012) as well as local preoptic astrocytes (Alvarez-Bolado et al., 2012). The neural-Shh-specific mutants mentioned above do not show strong phenotypes in the anterior portions of the hypothalamus beyond reduced growth and mild patterning defects (Szabó et al., 2009; Shimogori et al., 2010) and the phenotype of these anterior regions has not been investigated in Gli mutant mice (Theil et al., 1999; Park et al., 2000). Evidence for an important role of non-neural Shh in the development of the preoptic area was provided by a recent study that identified Lrp2, a member of the LDL receptor gene family, as a component of the Shh signaling pathway important for the induction of the preoptic ventral midline (Christ et al., 2012). Lrp2 is expressed broadly in the forebrain starting at E7.5, but expression gets restricted to the ventral midline by E9.5. Lrp2 sequesters secreted Shh protein and forms a complex with Ptch that regulates internalization and intracellular trafficking of Shh. In absence of $\operatorname{Lrp} 2$, the ventral tissue in the preoptic region fails to respond to Shh secreted from the prechordal mesoderm and medial Shh expression is not induced. Shh expression is shifted to two off-medial domains and Bmp4 and Gli3 are expressed in the ventral midline of the preoptic area in E10.5 Lrp2 knock-out mice. While Shh signaling is obviously required for the development of the preoptic area and alar hypothalamus (see also Pabst et al., 2000; Rallu et al., 2002a,b), we consider that the precise requirements for neural Shh in these regions have been insufficiently analyzed.

\section{REGULATION OF Shh EXPRESSION IN THE HYPOTHALAMUS}

The dynamic expression pattern of Shh during hypothalamic development raises the question on how this pattern is regulated. The transcription factor Six3 regulates Shh expression directly, and haploinsufficiency in Six3 results in the loss of Shh expression in the ventral midline, but only in the alar portion of the hypothalamus (Geng et al., 2008; Jeong et al., 2008; Figures 2A,B). Similarly, Sox2 has been shown to bind directly to the SBE2 enhancer and Sox2 and Sox3 have dose dependent effects on Shh expression in the midline of the alar hypothalamus (Zhao et al., 2012). Whether there is a similar transcription factor code required to induce $S h h$ expression in the ventral midline of the basal hypothalamus is unknown, but the mechanisms for the later downregulation of Shh expression in the midline have been investigated. In chick, BMPs act upstream of the transcription factor Tbx2 to inhibit Shh expression in the ventral midline of the basal hypothalamus, allowing this region to acquire its fate as a precursor area (Manning et al., 2006). In zebrafish, Wnt inhibition induces hypothalamic cell fate (Kapsimali et al., 2004) and in vitro experiments indicate that, in chick, BMPs act probably by antagonizing Wnt signaling in this region (Manning et al., 2006). A transcriptional mechanism that integrates Shh and Wnt signaling to regulate ventral specification has been suggested before in the spinal cord (Lei et al., 2006). In mouse, Tbx3 appears to be required to downregulate $S h h$ in the ventral midline and both Tbx 2 and Tbx 3 have the ability to suppress Shh expression by sequestering the transcription factor Sox2 away from the SBE2 forebrain enhancer (Trowe et al., 2013).

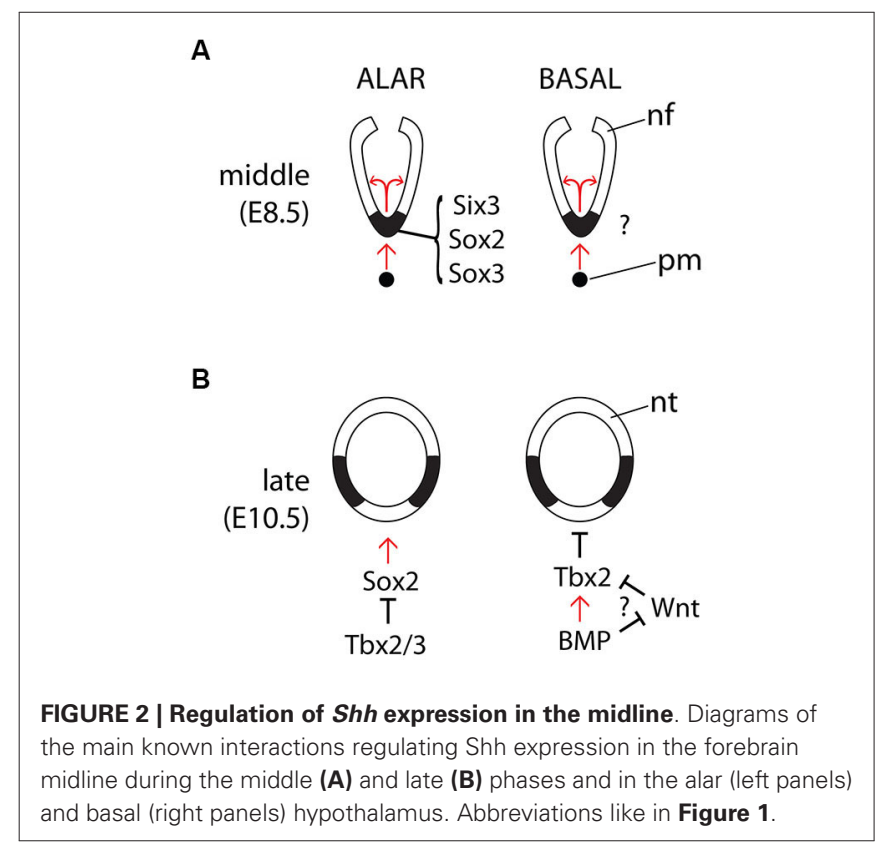




\section{CONCLUSION}

Ever since the first Shh knockout mouse (Chiang et al., 1996), our knowledge of the precise roles of Shh, prechordal or neuroepithelial, on hypothalamic specification and growth has steadily increased. Experimental approaches in chick and the phenotypical analysis of a variety of zebrafish and mouse mutants have demonstrated that prechordal Shh is necessary for midline specification, while neuroepithelial Shh plays a role in hypothalamic growth and in the specification of the lateral hypothalamic area. In addition to the functional insights, lineage tracing of neuroepithelial Shh in the hypothalamus has provided further important clues on hypothalamic development. Areas still in need of work are among others the specific Shh-Gli code for the different hypothalamic regions as well as elucidating the role of Shh on the alar hypothalamus (anterior hypothalamic region) and the preoptic area (a telencephalic area functionally included in the adult hypothalamus).

\section{REFERENCES}

Alvarez-Bolado, G., Paul, F. A., and Blaess, S. (2012). Sonic hedgehog lineage in the mouse hypothalamus: from progenitor domains to hypothalamic regions. Neural Dev. 7:4. doi: 10.1186/1749-8104-7-4

Aoto, K., Shikata, Y., Imai, H., Matsumaru, D., Tokunaga, T., Shioda, S., et al. (2009). Mouse Shh is required for prechordal plate maintenance during brain and craniofacial morphogenesis. Dev. Biol. 327, 106-120. doi: 10.1016/j.ydbio. 2008.11.022

Barth, K. A., and Wilson, S. W. (1995). Expression of zebrafish nk2.2 is influenced by sonic hedgehog/vertebrate hedgehog-1 and demarcates a zone of neuronal differentiation in the embryonic forebrain. Development 121, 1755-1768.

Blaess, S., Bodea, G. O., Kabanova, A., Chanet, S., Mugniery, E., Derouiche, A., et al. (2011). Temporal-spatial changes in Sonic hedgehog expression and signaling reveal different potentials of ventral mesencephalic progenitors to populate distinct ventral midbrain nuclei. Neural Dev. 6:29. doi: 10.1186/1749-81 04-6-29

Böse, J., Grotewold, L., and Rüther, U. (2002). Pallister-Hall syndrome phenotype in mice mutant for Gli3. Hum. Mol. Genet. 11, 1129-1135. doi: 10.1093/hmg/11. 9.1129

Chang, D. T., López, A., von Kessler, D. P., Chiang, C., Simandl, B. K., Zhao, R., et al. (1994). Products, genetic linkage and limb patterning activity of a murine hedgehog gene. Development 120, 3339-3353.

Chiang, C., Litingtung, Y., Lee, E., Young, K. E., Corden, J. L., Westphal, H., et al. (1996). Cyclopia and defective axial patterning in mice lacking Sonic hedgehog gene function. Nature 383, 407-413. doi: 10.1038/383407a0

Christ, A., Christa, A., Kur, E., Lioubinski, O., Bachmann, S., Willnow, T. E., et al. (2012). LRP2 is an auxiliary SHH receptor required to condition the forebrain ventral midline for inductive signals. Dev. Cell 22, 268-278. doi: 10.1016/j. devcel.2011.11.023

Clarren, S. K., Alvord, E. C. Jr., and Hall, J. G. (1980). Congenital hypothalamic hamartoblastoma, hypopituitarism, imperforate anus and postaxial polydactyly-a new syndrome? Part II: neuropathological considerations. Am. J. Med. Genet. 7, 75-83. doi: 10.1002/ajmg.1320070111

Dale, J. K., Vesque, C., Lints, T. J., Sampath, T. K., Furley, A., Dodd, J., et al. (1997). Cooperation of BMP7 and SHH in the induction of forebrain ventral midline cells by prechordal mesoderm. Cell 90, 257-269. doi: 10.1016/s00928674(00)80334-7

Dassule, H. R., Lewis, P., Bei, M., Maas, R., and McMahon, A. P. (2000). Sonic hedgehog regulates growth and morphogenesis of the tooth. Development 127 , 4775-4785.

Echelard, Y., Epstein, D. J., St-Jacques, B., Shen, L., Mohler, J., McMahon, J. A., et al. (1993). Sonic hedgehog, a member of a family of putative signaling molecules, is implicated in the regulation of CNS polarity. Cell 75, 1417-1430. doi: 10. 1016/0092-8674(93)90627-3

Flandin, P., Kimura, S., and Rubenstein, J. L. (2010). The progenitor zone of the ventral medial ganglionic eminence requires $\mathrm{Nkx} 2-1$ to generate most of the globus pallidus but few neocortical interneurons. J. Neurosci. 30, 2812-2823. doi: 10.1523/JNEUROSCI.4228-09.2010

Fuccillo, M., Joyner, A. L., and Fishell, G. (2006). Morphogen to mitogen: the multiple roles of hedgehog signalling in vertebrate neural development. Nat. Rev. Neurosci. 7, 772-783. doi: 10.1038/nrn1990

Furimsky, M., and Wallace, V. A. (2006). Complementary Gli activity mediates early patterning of the mouse visual system. Dev. Dyn. 235, 594-605. doi: 10. 1002/dvdy.20658

Geng, X., Speirs, C., Lagutin, O., Inbal, A., Liu, W., Solnica-Krezel, L., et al. (2008). Haploinsufficiency of Six3 fails to activate Sonic hedgehog expression in the ventral forebrain and causes holoprosencephaly. Dev. Cell 15, 236-247. doi: 10. 1016/j.devcel.2008.07.003

Goodrich, L. V., Johnson, R. L., Milenkovic, L., McMahon, J. A., and Scott, M. P. (1996). Conservation of the hedgehog/patched signaling pathway from flies to mice: induction of a mouse patched gene by hedgehog. Genes Dev. 10, 301-312. doi: 10.1101/gad.10.3.301

Hall, J. G., Pallister, P. D., Clarren, S. K., Beckwith, J. B., Wiglesworth, F. W., Fraser, F. C., et al. (1980). Congenital hypothalamic hamartoblastoma, hypopituitarism, imperforate anus and postaxial polydactyly-a new syndrome? Part I: clinical, causal and pathogenetic considerations. Am. J. Med. Genet. 7, 47-74. doi: 10.1002/ajmg.1320070110

Hui, C. C., Slusarski, D., Platt, K. A., Holmgren, R., and Joyner, A. L. (1994). Expression of three mouse homologs of the Drosophila segment polarity gene cubitus interruptus, Gli, Gli-2 and Gli-3, in ectoderm- and mesoderm-derived tissues suggests multiple roles during postimplantation development. Dev. Biol. 162, 402-413. doi: 10.1006/dbio.1994.1097

Jeong, Y., El-Jaick, K., Roessler, E., Muenke, M., and Epstein, D. J. (2006). A functional screen for sonic hedgehog regulatory elements across a $1 \mathrm{Mb}$ interval identifies long-range ventral forebrain enhancers. Development 133, 761-772. doi: 10.1242/dev.02239

Jeong, Y., Leskow, F. C., El-Jaick, K., Roessler, E., Muenke, M., Yocum, A., et al. (2008). Regulation of a remote Shh forebrain enhancer by the Six3 homeoprotein. Nat. Genet. 40, 1348-1353. doi: 10.1038/ng.230

Joksimovic, M., Anderegg, A., Roy, A., Campochiaro, L., Yun, B., Kittappa, R., et al. (2009). Spatiotemporally separable Shh domains in the midbrain define distinct dopaminergic progenitor pools. Proc. Natl. Acad. Sci. U S A 106, 19185-19190. doi: 10.1073/pnas.0904285106

Kapsimali, M., Caneparo, L., Houart, C., and Wilson, S. W. (2004). Inhibition of Wnt/Axin/beta-catenin pathway activity promotes ventral CNS midline tissue to adopt hypothalamic rather than floorplate identity. Development 131, 59235933. doi: 10.1242/dev.01453

Lee, J., Platt, K. A., Censullo, P., and Ruiz i Altaba, A. (1997). Gli1 is a target of Sonic hedgehog that induces ventral neural tube development. Development 124, 2537-2552.

Lei, Q., Jeong, Y., Misra, K., Li, S., Zelman, A. K., Epstein, D. J., et al. (2006). Wnt signaling inhibitors regulate the transcriptional response to morphogenetic ShhGli signaling in the neural tube. Dev. Cell 11, 325-337. doi: 10.1016/j.devcel. 2006.06.013

Lewis, P. M., Gritli-Linde, A., Smeyne, R., Kottmann, A., and McMahon, A. P. (2004). Sonic hedgehog signaling is required for expansion of granule neuron precursors and patterning of the mouse cerebellum. Dev. Biol. 270, 393-410. doi: 10.1016/j.ydbio.2004.03.007

Manning, L., Ohyama, K., Saeger, B., Hatano, O., Wilson, S. A., Logan, M., et al. (2006). Regional morphogenesis in the hypothalamus: a BMP-Tbx2 pathway coordinates fate and proliferation through Shh downregulation. Dev. Cell 11, 873-885. doi: 10.1016/j.devcel.2006.09.021

Marigo, V., Johnson, R. L., Vortkamp, A., and Tabin, C. J. (1996). Sonic hedgehog differentially regulates expression of GLI and GLI3 during limb development. Dev. Biol. 180, 273-283. doi: 10.1006/dbio.1996.0300

Marigo, V., and Tabin, C. J. (1996). Regulation of patched by sonic hedgehog in the developing neural tube. Proc. Natl. Acad. Sci. U S A 93, 9346-9351. doi: 10. 1073/pnas.93.18.9346

Mathieu, J., Barth, A., Rosa, F. M., Wilson, S. W., and Peyriéras, N. (2002). Distinct and cooperative roles for Nodal and hedgehog signals during hypothalamic development. Development 129, 3055-3065.

Matise, M. P., Epstein, D. J., Park, H. L., Platt, K. A., and Joyner, A. L. (1998). Gli2 is required for induction of floor plate and adjacent cells, but not most ventral neurons in the mouse central nervous system. Development 125, 27592770 . 
Meyer, N. P., and Roelink, H. (2003). The amino-terminal region of Gli3 antagonizes the Shh response and acts in dorsoventral fate specification in the developing spinal cord. Dev. Biol. 257, 343-355. doi: 10.1016/s0012-1606(03)00065-4

Nóbrega-Pereira, S., Gelman, D., Bartolini, G., Pla, R., Pierani, A., and Marín, O. (2010). Origin and molecular specification of globus pallidus neurons. J. Neurosci. 30, 2824-2834. doi: 10.1523/JNEUROSCI.4023-09.2010

Ohyama, K., Das, R., and Placzek, M. (2008). Temporal progression of hypothalamic patterning by a dual action of BMP. Development 135, 3325-3331. doi: 10 . 1242/dev.027078

Ohyama, K., Ellis, P., Kimura, S., and Placzek, M. (2005). Directed differentiation of neural cells to hypothalamic dopaminergic neurons. Development 132, 51855197. doi: 10.1242/dev.02094

Ohyama, K., Ikeda, E., Kawamura, K., Maeda, N., and Noda, M. (2004). Receptorlike protein tyrosine phosphatase zeta/RPTP beta is expressed on tangentially aligned neurons in early mouse neocortex. Brain Res. Dev. Brain Res. 148, 121127. doi: 10.1016/j.devbrainres.2003.10.012

Pabst, O., Herbrand, H., Takuma, N., and Arnold, H. H. (2000). NKX2 gene expression in neuroectoderm but not in mesendodermally derived structures depends on sonic hedgehog in mouse embryos. Dev. Genes Evol. 210, 47-50. doi: $10.1007 / \mathrm{pl} 00008188$

Park, H. L., Bai, C., Platt, K. A., Matise, M. P., Beeghly, A., Hui, C. C., et al. (2000). Mouse Gli1 mutants are viable but have defects in $\mathrm{SHH}$ signaling in combination with a Gli2 mutation. Development 127, 1593-1605.

Pera, E. M., and Kessel, M. (1997). Patterning of the chick forebrain anlage by the prechordal plate. Development 124, 4153-4162.

Placzek, M., and Briscoe, J. (2005). The floor plate: multiple cells, multiple signals. Nat. Rev. Neurosci. 6, 230-240. doi: 10.1038/nrn1628

Platt, K. A., Michaud, J., and Joyner, A. L. (1997). Expression of the mouse Gli and Ptc genes is adjacent to embryonic sources of hedgehog signals suggesting a conservation of pathways between flies and mice. Mech. Dev. 62, 121-135. doi: 10.1016/s0925-4773(96)00648-x

Puelles, L., Martinez-de-la-Torre, M., Bardet, S., and Rubenstein, J. L. R. (2012). "Hypothalamus," in The Mouse Nervous System, eds C. Watson, G. Paxinos and L. Puelles (San Diego: Elsevier-Academic Press), 221-312.

Rallu, M., Corbin, J. G., and Fishell, G. (2002a). Parsing the prosencephalon. Nat. Rev. Neurosci. 3, 943-951. doi: 10.1038/nrn989

Rallu, M., Machold, R., Gaiano, N., Corbin, J. G., McMahon, A. P., and Fishell, G. (2002b). Dorsoventral patterning is established in the telencephalon of mutants lacking both Gli3 and hedgehog signaling. Development 129, 4963-4974.

Shimamura, K., Hartigan, D. J., Martinez, S., Puelles, L., and Rubenstein, J. L. (1995). Longitudinal organization of the anterior neural plate and neural tube. Development $121,3923-3933$.

Shimogori, T., Lee, D. A., Miranda-Angulo, A., Yang, Y., Wang, H., Jiang, L., et al. (2010). A genomic atlas of mouse hypothalamic development. Nat. Neurosci. 13 , 767-775. doi: 10.1038/nn.2545
Szabó, N. E., Zhao, T., Cankaya, M., Theil, T., Zhou, X., and Alvarez-Bolado, G. (2009). Role of neuroepithelial Sonic hedgehog in hypothalamic patterning. J. Neurosci. 29, 6989-7002. doi: 10.1523/jneurosci.1089-09.2009

Theil, T., Alvarez-Bolado, G., Walter, A., and Rüther, U. (1999). Gli3 is required for Emx gene expression during dorsal telencephalon development. Development 126, 3561-3571.

Trowe, M. O., Zhao, L., Weiss, A. C., Christoffels, V., Epstein, D. J., and Kispert, A. (2013). Inhibition of Sox2-dependent activation of Shh in the ventral diencephalon by Tbx3 is required for formation of the neurohypophysis. Development 140, 2299-2309. doi: 10.1242/dev.094524

Wei, B., Huang, Z., He, S., Sun, C., You, Y., Liu, F., et al. (2012). The onion skin-like organization of the septum arises from multiple embryonic origins to form multiple adult neuronal fates. Neuroscience 222, 110-123. doi: 10.1016/j. neuroscience.2012.07.016

Xu, Q., Tam, M., and Anderson, S. A. (2008). Fate mapping Nkx2.1-lineage cells in the mouse telencephalon. J. Comp. Neurol. 506, 16-29. doi: 10.1002/cne. 21529

Zhao, L., Zevallos, S. E., Rizzoti, K., Jeong, Y., Lovell-Badge, R., and Epstein, D. J. (2012). Disruption of SoxB1-dependent Sonic hedgehog expression in the hypothalamus causes septo-optic dysplasia. Dev. Cell 22, 585-596. doi: 10. 1016/j.devcel.2011.12.023

Zhao, T., Zhou, X., Szabó, N., Leitges, M., and Alvarez-Bolado, G. (2007). Foxb1-driven Cre expression in somites and the neuroepithelium of diencephalon, brainstem and spinal cord. Genesis 45, 781-787. doi: 10.1002/dvg. 20356

Conflict of Interest Statement: The Guest Associate Editor Valery Grinevich declares that, despite being affiliated to the same institution as authors Roberta Haddad-Tóvolli, Xunlei Zhou and Gonzalo Álvarez-Bolado, the review process was handled objectively and no conflict of interest exists. The authors declare that the research was conducted in the absence of any commercial or financial relationships that could be construed as a potential conflict of interest.

Received: 31 October 2014; paper pending published: 19 November 2014; accepted: 02 December 2014; published online: 06 January 2015.

Citation: Blaess S, Szabó N, Haddad-Tóvolli R, Zhou X and Álvarez-Bolado G (2015) Sonic hedgehog signaling in the development of the mouse hypothalamus. Front. Neuroanat. 8:156. doi: 10.3389/fnana.2014.00156

This article was submitted to the journal Frontiers in Neuroanatomy.

Copyright (c) 2015 Blaess, Szabó, Haddad-Tóvolli, Zhou and Álvarez-Bolado. This is an open-access article distributed under the terms of the Creative Commons Attribution License (CC BY). The use, distribution and reproduction in other forums is permitted, provided the original author(s) or licensor are credited and that the original publication in this journal is cited, in accordance with accepted academic practice. No use, distribution or reproduction is permitted which does not comply with these terms. 